ESTUDIOS $\lambda$ AMBDA.

Teoría y práctica de la didáctica

en lengua y literatura

\title{
Literatura: arte de educar y maleducar con la palabra
}

(Literature: art of educating and miseducating with words)

\section{Fortino Corral Rodríguez iD, Universidad de Sonora, Hermosillo, Sonora, México}

\author{
Volumen 6, Número 1 \\ Enero - junio de 2021 \\ p. $31-38$
}

Este número se publicó el 10 de enero de 2021

Reseña recibida: 10 de noviembre de 2020

Reseña aceptada para publicación: 15 de diciembre de 2020

ISSN: 2448-5942, https://doi.org/10.36799/el.v6i1.112

\section{RECENSIÓN}

Citar este artículo como:

Corral Rodríguez, F. (2021). Literatura: arte de educar y maleducar con la palabra. Estudios $\lambda a m b d a$. Teoría y Práctica de la Didáctica en Lengua y Literatura., 6(1), 31 - 38. https://doi.org/10.36799/el.v6i1.112

Derechos de autor: Las personas autoras conservan en todo momento sus derechos morales y patrimoniales sobre la obra; la obra no se puede alterar, transformar o ampliar; siempre debe reconocerse la autoría del documento referido. Ninguna de las modalidades de los documentos publicados en Estudios Aambda. Teoría y práctica de la didáctica en lengua y literatura tienen fines comerciales de naturaleza alguna.

Los contenidos de este artículo están bajo una licencia de Creative Commons Atribución No Comercial- Sin Derivadas 4.0 Internacional cc) (1) () 


\title{
Literatura: arte de educar y maleducar con la palabra
}

\author{
(Literature: art of educating and miseducating with words)
}

FORTINO CORRAL RODRÍGUEZ ${ }^{1}$

\section{RESUMEN}

Los textos que reúne el libro Río sin riberas, de Francisco González, revelan un encuentro virtuoso entre pedagogía y literatura. Vida propia y espíritu universitario se entrelazan lúdica y estéticamente en los relatos, ensayos y poemas que integran este conjunto. El libro constituye una selección, realizada por el propio autor, de los distintos terrenos en que ha incursionado: la investigación académica, la docencia, la polémica, la creatividad, el humor. En todo ello se percibe un espíritu provocador que busca remover esquemas de sensibilidad y pensamiento.

PALABRAS CLAVE: pedagogía, singularización, biografía, creatividad.

\section{ABSTRACT}

Texts compiled in Río sin riveras (River with no Banks), by Francisco González, expose an uplifting encounter between pedagogy and literature. Both proper life and university spirit weave aesthetic and ludic ways into stories, essays and poems that make up this unit. The book constitutes a digest, diverse genre selected by its own author, from the distinct areas in which he has explored: academic research, teaching, polemics, creativity, humor. In all these aspects it is perceived a provocateur that tries to remove established schemes of sensibility and thought.

KEYWORDS: pedagogy, singularity, biography, creativity

\section{RECENSIÓN}

El libro Río sin riberas de Francisco González Gaxiola, reúne obra variada: artículos, ensayos narraciones y poemas. Su título es más que elocuente para expresar la poética literaria y pedagógica de su autor. Se trata de un río cuya meta no es llegar al mar, sino solazarse en su andar. Su quehacer no se define por el futuro, sino por el presente. Responde no a la lógica del deber, sino a la exigencia del ser.

\footnotetext{
${ }^{1}$ El Dr. Fortino Corral Rodríguez es profesor investigador en el Departamento de Letras y Lingüística de la Universidad de Sonora, miembro del cuerpo académico Literatura, Lengua y Cultura, sus líneas de investigación son: Literatura periféricas, y procesos de significación y representación en la literatura y la cultura. ORCID https://orcid.org/0000-0002-8933-3957, correo electrónico, fortino.corral@,unison.mx
}

Reseña recibida: 10 de noviembre de 2020

Reseña aceptada para publicación: 15 de diciembre de 2020 
El libro consta de cuatro secciones. La primera, mucho más breve que las otras, se compone de cuatro artículos de divulgación sobre cuestiones literarias. Las otras tres conforman prácticamente el cuerpo del libro; son más o menos del mismo grosor y se agrupan según el género literario: "Ensayos", “Autobiografía” y "Creación: relato, cuento, poemas.” En realidad, esta última sección podría denominarse "Poesía" ya que está integrada básicamente por poemas, y los dos textos narrativos que ahí figuran -muy breves, por cierto- podrían haber sido colocados en "Autobiografía", y nadie hubiera protestado por ello. Pero se trata de un río sin riberas, y estos desbordes son peccata minuta.

Aunque breve, la primera sección es significativa pues condensa los elementos temáticos y composicionales de todo el libro. De los cuatro artículos de divulgación que conforman este conjunto, el primero, titulado "A través de la literatura. Extrañarnos de lo cotidiano”, es el más revelador. Consiste en un comentario sobre el ensayo señero de Víctor Schkolvski, una de las mentes más brillantes del formalismo ruso. Veo en este ensayo la base programática no solo de la obra literaria de Francisco González, sino de todo su quehacer pedagógico. ¿A qué me refiero? La idea central del teórico ruso es que la función primordial de la literatura y el arte se cifra en perturbar la percepción automatizada o adormecida que ordinariamente tenemos del mundo. De acuerdo con esta concepción, el arte tiene como cometido renovar nuestra mirada sobre el mundo, lo cual realiza mediante estrategias sui géneris de singularización y extrañamiento. Es claro que el autor de Río sin riberas comulga con el planteamiento de Schklovsky, lo cual le perfila como un creador lúdico y provocador.

En estos primeros textos se aprecia también el ethos pedagógico del autor. Muy cercano a la socarronería maliciosa de Sócrates, desde una cátedra identificada tradicionalmente con el laicismo y el materialismo filosófico, González invita a sus estudiantes a leer la Biblia. Pero a medio camino advierte:

La Biblia es un libro extraordinario porque muestra en toda su crudeza historias que hablan de las pasiones humanas. Desde un punto de vista literario, en ella podemos leer los relatos más francos y desprejuiciados de seducción, exhibicionismo, voyerismo, erotismo, lujuria, traición, adulterio, incesto y asesinatos ... La Biblia es definitivamente un libro para adultos. (p. 22) 
Bueno, no olvidemos que Sócrates decía que lo acompañaba siempre un demonio. Por otro lado, y emulando la inocencia de un Principito tardío, importuna al lector con la inopinada pregunta de por qué en la vida y en la literatura son necesarios los finales. Esta pregunta reaparece en la siguiente sección, "Ensayos”, en la cual le dedica un sesudo trabajo. Finalmente, queda por mencionar el artículo "La narrativa da sentido al mundo". En sólo dos páginas y media moviliza con prodigioso pulso didáctico categorías y conceptos de la filosofía, la teoría literaria, la psicología y otras disciplinas, para mostrar la omnipresencia de la narratividad como estructura cognitiva, hecho al que no escapan las llamadas ciencias duras. Concluye observando que las historias despliegan un proceso doble: por un lado, representan aspectos del mundo y, por otro, crean mundos, de modo que "la naturaleza de la narrativa es contradictoria, ambigua, polisémica, con al menos dos niveles de interpretación".

La sección de ensayos contiene cinco textos. Dos de ellos son sobre literatura sonorense; otros dos, sobre la problemática de la enseñanza de la literatura; y uno más, el que ya mencionamos antes, corresponde al ámbito de la teoría literaria: por qué terminan las historias. La literatura sonorense ha sido tema permanente de interés para Francisco González. Su tesis doctoral, cristalizada después en el libro El exilio interior mexicano, se enfocó en el estudio de cuatro obras de sendos escritores sonorenses: Leo Sandoval, Sergio Valenzuela, Armida de la Vara y Gerardo Cornejo. La selección de las obras responde, a parte de la adscripción cultural mencionada (ser sonorense), a un rasgo genérico que comparten las cuatro obras y que también le ha ocupado de manera orgánica: la cuestión autobiográfica en la literatura. Tanto lo regional como lo biográfico se ubican en las riberas de lo que podríamos identificar como el río de la literatura canónica, unas riberas que son y no son parte de ese río.

En lo que respecta a los textos dedicados al problema de la enseñanza de la literatura, es justo decir que, entre los profesores de literatura del Depto. de Letras y Lingüística, González ha sido quien más se ha ocupado de atender a los egresados que se han dedicado a la docencia en el nivel medio superior. Para una mejor comprensión de los dos textos que aquí aparecen, es preciso mencionar que, desde hace algunos años, el autor de Río sin riberas inició la organización de los Congresos de Enseñanza de la Lengua y la Literatura y que continúa el frente de éste. Dicho congreso es un foro al que los egresados y egresadas de literatura y lingüística dedicados acuden religiosamente cada dos años en busca de retroalimentación para su quehacer profesional 
como profesores de lengua y literatura... o en busca de consuelo para sus afanes. Me consta que, en este último caso, el profesor González ha sabido actuar como el oráculo de Delfos: "ni dice, ni calla, sólo hace señales.”

Para el autor del libro que ahora comentamos, la literatura y la enseñanza de esta conforman una unidad indisociable que tiene que ver con la formación íntegra del ser humano:

En síntesis, no buscamos cumplir el objetivo estético únicamente, logro digno de por sí, pero si solo a esto se redujera resultaría cuestionable. Esta propuesta se fundamenta en un objetivo válido para todo nivel escolar: el de hacer crecer al estudiante en emoción, sentimiento y razón; se busca la manera de volverlo persona creativa, analítica, crítica, de actitud abierta y tolerante, persona despojada de prejuicios, desconfiada ante los conocimientos terminados, y siempre cuestionadora del dogma y la autoridad impuesta. (p. 64)

El ensayo "Por qué terminan las historias" obliga a repensar esa noción tan sedimentada en nuestra cultura de que el sentido de toda narración descansa en su desenlace, para lo cual, desde luego, no faltan ejemplos. Sin embargo, también hay contraejemplos: historias que después de concluidas, han sido reabiertas y continuadas. Intuyo que lo que condujo al autor a esta pregunta fue justamente el género autobiográfico: este es inconcluso por su misma condición estructural ya que el protagonista no puede narrar su propia muerte. Cada una de las historias que el narrador-personaje narra sobre sí mismo o sobre otros posee necesariamente un final parcial, episódico, por el hecho de estar inserta en una historia mayor, la propia, cuyo final no puede ser narrado.

Y pasamos de esta manera a la sección "Biografía". De los once relatos que la integran, cinco tratan asuntos del entorno familiar; de estos, cuatro remiten a la infancia del autor en Mocorito, Sinaloa y en Cd. Obregón y uno a la vida adulta, sobre la muerte de su padre. Las seis narraciones restantes refieren eventos vinculados, de una u otra manera, con la Universidad de Sonora. En todos los relatos se aprecia el gusto por recuperar y revivir experiencias propias o de otros que implican un giro singular en la percepción. Escojo entre muchos este pasaje en que el autor describe el disfrute que, cuando era niño, le reportaba jugar a las casitas: "Me acostaba en el suelo boca arriba, luego metía la cabeza. La oscuridad, el olor fresco de las ramas y el sabor agridulce de los frutos me proporcionaban un placer infinito en su sencillez" (p. 139). 
Pero mi historia favorita es la titulada "Enrique Valle Flores. Mi personaje inobjetable." Una narración nostálgica, pintoresca, divertida, aleccionadora; un personaje entrañable, insolente, sabio, caprichoso y enigmático. El profesor González narra sus experiencias como alumno, como "secretario perpetuo" y como compañero asiduo de tertulias de este personaje inobjetable; narra un tiempo y un espacio evanescente, una universidad íntima y épica a la vez, que se nos ha escabullido para siempre.

En la última sección, titulada "Creación: relato, cuento, poemas", se incluye completo el poemario Historias perdidas en la arena, publicado en 1996 y 2000. También se incluyen dos textos narrativos que, como ya comenté antes, podrían haberse colocado en la sección de "Autobiografía", aunque tal vez el criterio para ubicarlos en esta parte fue el de remarcar su carácter ficcional. El término creación podría englobar perfectamente las narraciones biográficas, pero al ser usado para designar esta otra sección, lo que hace es reforzar el carácter inventivo y ficcional de estos textos.

En los paratextos del poemario Historias perdidas se indica que la edición española (ojo, hubo entonces una primera versión en otro idioma) estuvo a cargo de una académica adscrita a una prestigiosa universidad norteamericana; se supone que esta eminencia es la autora de las observaciones críticas que se hacen sobre cada poema en notas de pie de página, conjetura que se refuerza por el hecho de que hay por ahí un par de autoalusiones en femenino. Ahora bien, en el primero de estos textos de presentación, titulado "Prólogo a la segunda edición", firmado por Ramón Miranda Camou, se menciona que, en conversaciones informales con Francisco González, éste confesó que tal profesora era pura ficción suya. Confieso que dudé entonces de la existencia de Miranda Camou y caí en la trampa de googlearlo. Corroboré que apenas existe... pero existe: exsacerdote con estudios de Historia; traductor de algún libro del finado Julio Montané.

Entre estos paratextos figura también un "Prólogo" firmado por Francisco González Gaxiola, en Bahía Kino y fechado en la primavera del 95. Sin embargo, en un texto previo titulado "Presentación" aclara: "Para todas mis composiciones certifico de referencia el lugar cercano y cotidiano de Bahía Kino, Sonora. Debo confesar, sin embargo, que esta referencia, este lugar sólo es poético, porque en realidad nunca lo visité en la primavera del ‘95” (177). 
Los lectores de esta reseña notarán que me he limitado a comentar los paratextos del poemario y no he dicho nada sobre los poemas mismos. Esto es sencillo de explicar. Si el profesor González se inventó una voz crítica para los poemas, nada puede garantizarnos que no se inventó también al poeta, al autor de los poemas, y lo que tenemos es el juego de dos autores ficticios. Esta estrategia de crear otro autor no debe confundirse con el uso de pseudónimo, como lo explica muy bien Octavio Paz en su ensayo sobre Fernando Pessoa. Sospecho que Francisco se ha creado dos heterónimos: el de la catedrática, a la que llama Jane Lambers Lusenstein, y el del poeta, al que tramposamente bautiza con su propio nombre: Francisco González Gaxiola.

Por todo lo anterior, considero ocioso emitir juicio de valor alguno sobre estos poemas y sobre las glosas críticas que los acompañan. Sospecho que se trata de un terreno minado en que la erudición de la académica puede ser falsa erudición, es decir, una parodia del academicismo por parte de González; y el lirismo del poeta, un pseudolirismo: sus torpezas compositivas pueden constituir pseudotorpezas y sus ingenuidades, malicia vil de nuestro autor. Debo reconocer que estuve a punto de entrar en controversia con las notas críticas de la presunta colega norteamericana: estuve a punto de discutir con un fantasma. Pero si he de emitir algún juicio sobre estos poemas, diré que mi favorito es uno que se titula "Olvido". Aparece el título en la parte superior, luego el inmenso espacio de la página en blanco y en la parte inferior, la infaltable nota de la Dra. Lusenstein que dice: "No se puede columbrar si el autor esté jugando con la ambigüedad del título y su referente o haya realmente sido un olvido" (203). Un poema de antología.

Como ha podido apreciarse, en las cuatro secciones que integran el libro, el autor luce una gran habilidad para mostrarse y ocultarse, para mostrar el mundo y ocultarlo y otra vez mostrarlo; el libro es un espejo caprichoso en el que nos reconocemos y desconocemos: todo un artefacto de extrañamiento, como lo sugería el teórico ruso.

\section{Referencias:}

González Gaxiola, F. Río sin riberas. Instituto Sonorense de Cultura-Universidad de Sonora, 2018. 
